\title{
The development of a spinal algorhythmic for evaluation of scoliosis Biagio Iemolo
}

\author{
Address: I.S.C. (Italian Spine Center), Via dei Mille n. 238 Vittoria 97019 (Rg), Italy \\ from $5^{\text {th }}$ International Conference on Conservative Management of Spinal Deformities \\ Athens, Greece. 3-5 April 2008 \\ Published: 15 January 2009 \\ Scoliosis 2009, 4(Suppl I):O7I doi:I0.II86/I748-7|6I-4-SI-O7|
}

This abstract is available from: http://www.scoliosisjournal.com/content/4/SI/O7I

(C) 2009 lemolo; licensee BioMed Central Ltd.

\section{Objective}

The conservative management of scoliosis and related spinal deformities must be precise. A prompt evaluation of various somatic-radiological parameters and an accurate record of the spinal data are required during treatment.

Our purpose is to present a spinal algorhythmic to facilitate documentation of treatments for various spinal diseases during growth.

\section{Study design}

Seven types of parameters are considered:

1) growth (height, seated height, weight, lower extremity length inequality etc.)

2) clinical frontal plane (rib hump height, Bunnel, pelvic balance etc.)

3) radiological frontal plane (Cobb-Perdriolle degrees, Risser, etc.)

4) clinical sagittal plane (sagittal distances from the plumb line, pelvic balance, etc.)

5) radiological sagittal plane (angle of kyphosis, lordosis, sacrum, etc.)

6) muscular-neuromotor integration (pectoral, psoas muscles retraction etc.)

7) unstable equilibrium (Romberg, knee-vestibular test, Fukuda-Unterberger, etc.)

\section{Results}

This spinal algorhythmic allowed us to obtained early and accurate identification of progressive deformities. In addi- tion, we were able to facilitate the treatment of spinal diseases for all of the patients.

\section{Conclusion}

During growth, we believe that the various types of spinal deformities require prompt, careful and appropriate treatment recommendations.

This spinal algorhythmic is proposed to aid in the immediate evaluation of a deformity. The goals are to define the categories of scoliosis, kyphosis, spondilolysthesis and to quantize the magnitude of the spinal deformities.

This criteria easily recognizes all of the patient categories, identifies progressive deformities, and describes indications for their treatment.

\section{References}

I. Asher MA, Burton DC: Adolescent idiopathic scoliosis: natural history and long term treatment effects. Scoliosis 2006, I:2.

2. Negrini S, Aulisa L, Ferraro C, et al.: Linee guida nazionali (Trattamento riabilitativo del paziente in età evolutiva affetto da deformità del rachide). Monografia G.S.S 2002, 68:15-16.

3. Bunnell WP: Selective screening for scoliosis. Clin Orthop Relat Res 2005:40-5.

4. Grosso C, Negrini S, Boniolo A, et al.: The validity of clinical examination in adolescent spinal deformities. Stud Health Technol Inform 2002, 91:23-5.

5. Weiss HR, Negrini S, Rigo M, et al.: Indications for conservative management of scoliosis (guidelines). Scoliosis 2006, I:5. 